\title{
Effect of Changing Theoretical Maximum Specific Gravity on Asphalt Mixture Design
}

\author{
Mohamed A. G. E1 Sayed \\ Department of Construction Engineering and Utilities, Faculty of Engineering, Zagazig University., \\ Zagazig, Egypt \\ E-mail: mabdelghany67@gmail.com
}

\begin{abstract}
The value of theoretical maximum specific gravity of bituminous paving mixture $\left(\mathrm{G}_{\mathrm{mm}}\right)$ plays a significant role in the performance of paving mixes. The Impact of $\left(\mathrm{G}_{\mathrm{mm}}\right)$ can be noticed on properties of bleeding, rutting, raveling, and fatigue. Calculation of $\mathrm{G}_{\mathrm{mm}}$ is fundamental to the design process of asphalt concrete mixes. It can be measured either directly by using the standard Rice test method (AASHTO T209, ASTM D2041), or can be estimated indirectly based on the effective specific gravity of aggregate mixtures, and specific gravity of asphalt. In the latter case exact determination of percentage air voids, and optimum asphalt content values is pivotal in estimating the true value of $G_{\mathrm{mm}}$. This paper aims to study the Impact of changing theoretical maximum specific gravity for asphalt mixture on the characteristic of asphalt mixes. To achieve this objective an extensive experimental program was designed. Two types of aggregates (limestone and basalt) as well as four mix gradations were used to conduct the study. Based on the study results, it has been found that the measured air voids content using $G_{m m}$ value measured by rice test $\left(A V_{m}\right)$ is lower than the estimated air voids content $\left(A V_{e}\right)$ in about $20 \%$ and $9 \%$ for limestone and basalt, respectively. Consequently, the optimum asphalt content values based on the laboratory-measured $\mathrm{G}_{\mathrm{mm}}\left(\mathrm{AC}_{\mathrm{m}}\right)$ are lower than those which were determined by using the estimated $\mathrm{G}_{\mathrm{mm}}\left(\mathrm{AC}_{\mathrm{e}}\right)$ by about $7 \%$ and $2 \%$ for limestone and basalt, respectively. Therefore, it is recommended to use the rice test in determining the theoretical maximum specific gravity of asphalt mixture in Egyptian code.
\end{abstract}

Keywords: Theoretical maximum specific gravity of a bituminous paving mixture $\left(G_{\mathrm{mm}}\right)$, rice test, percent air voids, optimum asphalt content, limestone, basalt.

ENGINEERING JOURNAL Volume 16 Issue 4

Received 9 January 2012

Accepted 7 May 2012

Published 1 July 2012

Online at http://www.engj.org/

DOI:10.4186/ej.2012.16.4.137 


\section{Introduction}

The theoretical maximum specific gravity of a bituminous paving mixture $\left(G_{\mathrm{mm}}\right)$ represents the maximum theoretical mass of a unit volume of mixture composed entirely of impermeable aggregate coated with asphalt, in other words, no air voids present in the mixture. Maximum specific gravity is required to determine the mixture's asphalt absorption, percent of air voids in the compacted bituminous paving mixture, percent of voids in mineral aggregate. Moreover, it is essential to determine the target values for the compaction. Theoretical maximum specific gravity is a critical Hot Mix Asphalt (HMA) characteristic because it is used to calculate the percent of air voids in compacted HMA.

The Percent of air voids in HMA pavement is important because it has a profound effect on long-term pavement performance [1]. An approximate "rule-of-thumb" is for every one percent increase in air voids (above 6-7 percent); accordingly, about 10 percent of the pavement life may be lost [1] [2]. The rule-ofthumb was developed using limited project data; therefore, it should be used with extreme caution and applied to air voids above $6-7$ percent. According to Roberts et al. [3], there is considerable evidence that dense graded mixes should not exceed 8 percent nor fall below 3 percent air voids during their service life. Air voids that are either too great or too low can cause a significant reduction in pavement life [1]. For dense graded HMA, air voids between 3 and 8 percent generally produce the best compromise of pavement strength, fatigue life, durability, raveling, rutting and moisture damage susceptibility. High air void content (above 8 percent) or low air void content (below 3 percent) may cause several pavement distresses. Examples of the distresses for dense-graded HMA are; (a) Decreased stiffness and strength, tensile strength, static and resilient moduli ;moreover, the stability is reduced at high air void content [1]; (b) reduced fatigue life, fatigue properties can be reduced by 30 to 40 percent for each one percent increase in air void content; (c) accelerated aging/decreased durability; (d) raveling, raveling becomes a significant problem above about eight percent air voids and becomes a severe problem above approximately 15 percent air voids [1]; (e) rutting, the amount of rutting which occurs in an asphalt pavement is inversely proportional with the air void content [1] [4]; (f) moisture damage, air voids in insufficiently compacted HMA are high and tend to be interconnected with each other. Numerous and interconnected air voids allow for easy water entry [1] which increases the possibility of significant moisture damage.

In designing the pavement mixture by MARSHALL design method, $\mathrm{G}_{\mathrm{mm}}$ is needed at each asphalt content to calculate the percent of air voids. Some agencies require performing the Rice test at each asphalt content level. Other agencies allow the Rice test to be run at two asphalt contents preferably on mixes at or near optimum asphalt content and then calculating $G_{\mathrm{mm}}$ at other asphalt content levels. From these tests, which are based on the effective specific gravity of the aggregate, $\left(\mathrm{G}_{\mathrm{se}}\right)$ derived from the test results [5].

The effective specific gravity $\left(G_{\mathrm{se}}\right)$ of the aggregate can be calculated from the measured values of $\left(\mathrm{G}_{\mathrm{mm}}\right)$, using the following equation:

$$
G_{s e}=\frac{P_{m m}-P_{b}}{\frac{P_{m m}}{G_{m m}}-\frac{P_{b}}{G_{b}}}
$$

In addition, the $G_{\mathrm{mm}}$ of any other asphalt content can be obtained using the following equation:

$$
G_{m m}=\frac{P_{m m}}{\frac{P_{s}}{G_{s e}}+\frac{P_{b}}{G_{b}}}
$$

where

$\mathrm{G}_{\mathrm{se}} \quad=$ effective specific gravity of aggregate,

$\mathrm{G}_{\mathrm{mm}}=$ theoretical maximum specific gravity of paving mixture,

$\mathrm{P}_{\mathrm{mm}} \quad=$ percent by mass of total loose mixture $=100$,

$\mathrm{P}_{\mathrm{b}} \quad=$ asphalt content at which test was performed, percent by total mass of mixture,

$\mathrm{G}_{\mathrm{b}} \quad=$ specific gravity of asphalt, and

$\mathrm{P}_{\mathrm{s}} \quad=$ aggregate content, percent by total mass of mixture.

In fact, the effective specific gravity $\left(\mathrm{G}_{\mathrm{se}}\right)$ is assumed to be constant in Eq. (2), and this is valid since asphalt absorption does not change with varying the asphalt content.

According to the procedures of MARSHALL design method, which is mentioned in the Egyptian code for urban and rural works [6], $\left(\mathrm{G}_{\mathrm{mm}}\right)$ is estimated based on the effective specific gravity of the aggregate mixtures and specific gravity of asphalt, as shown in Eq. (2). The procedures of MARSHALL method 
mentioned in the code don't include the Rice test for measuring $G_{\mathrm{mm}}$. The effective specific gravity of aggregate mixture is assumed to be equal to the saturated surface dry specific gravity or to the average value of the bulk. Furthermore, the apparent specific gravity of aggregate mixture was detailed on preparation and construction of the road projects handbook of general authority of roads and bridges and land transport [7]

The two methods of determining the $\mathrm{G}_{\mathrm{mm}}$ in asphalt mixtures, discussed in this research, are as follows:

1) Measuring $G_{m m}$ using the Rice test. It will be referred to, as $G_{m m}-m[8,9]$.

2) Estimating $G_{m m}$ using the effective specific gravity of aggregate mixtures which assumed to be equal to the following $[6,7]$ :

a) Saturated surface dry specific gravity. It will be referred to, as $G_{m m}-e_{1}$ [7].

b) Average value of bulk and apparent specific gravity. It will be referred to, as $G_{m m}-e_{2}[7]$.

Based on MARSHALL design method, the maximum specific gravity of a bituminous paving mixture $\left(\mathrm{G}_{\mathrm{mm}}\right)$ was determined through the standard test method, AASHTO T209 [8], ASTM D2041 [9] that is called Rice test (named after James Rice, who developed the test procedure) $[5,10]$.

\subsection{Rice Method}

Rice test is used for determining the theoretical maximum specific gravity $\left(\mathrm{G}_{\mathrm{mm}}\right)$ of un-compacted Hot Mix Asphalt (HMA) paving mixtures at $25^{\circ} \mathrm{C}\left(77^{\circ} \mathrm{F}\right)$ in accordance with AASHTO T209 [8], ASTM D2041 [9] procedures. The Apparatus of this test includes containers with vacuum bowls and vacuum flask to weigh in air only, scale; in addition, it contains vacuum pump or water aspirator, residual pressure manometer or calibrated absolute pressure gage, manometer or vacuum gage, thermometers, water bath, bleeder valve, mechanical agitation device, and oven. Figure 1 shows the rice test apparatus. A weighed sample of ovendry paving mixture in the loose condition is placed in a tarred vacuum vessel. Sufficient water at a temperature of $25^{\circ} \mathrm{C}\left(77^{\circ} \mathrm{F}\right)$ is added to completely submerge the sample. Vacuum is gradually applied to reduce the residual pressure in the vacuum vessel to $4 \mathrm{kPa}(30 \mathrm{~mm}$ of $\mathrm{Hg}$ ) or less. Then, it held for $15 \pm 2$ min. At the end of the vacuum period, the vacuum is gradually released. The volume of the sample of the paving mixture is obtained by immersing the vacuum container with the sample in water bath then weighs it, or by fills the vacuum container level full of water and weighs it in air. Both the temperature and mass are measured at this time. From the mass and volume measurements, the specific gravity or density of aggregate is obtained at $25^{\circ} \mathrm{C}$.

The Air voids, $\mathrm{P}_{\mathrm{a}}$, in the total compacted paving mixture consist of the small air spaces between the aggregate particles. The volume percentage of air voids in a compacted mixture can be determined using the following equation [5]:

$$
P_{a}=100 \times \frac{G_{m m}-G_{m b}}{G_{m m}}
$$

As appear from Eq. (3), $P_{a}$ is directly proportional to $G_{m m}$ value. From the previous discussions, it can concluded that $G_{m m}$ value, estimated by Eq. (2) which used in the Egyptian procedures for MARSHALL design of pavement mix, is directly proportional to the assumed value of effective specific gravity of aggregate mixture $\left(\mathrm{G}_{\mathrm{se} e}\right.$, as clear in Eq. (2).

\subsection{Study Problem Statement}

Based on MARSHALL design method, the maximum theoretical specific gravity of a bituminous paving mixture $\left(G_{\mathrm{mm}}\right)$ is measured through a standard test method, AASHTO T209, ASTM D2041 that is called Rice test. However, according to the procedures of MARSHALL design method mentioned in the Egyptian code for urban and rural works [6], $\left(\mathrm{G}_{\mathrm{mm}}\right)$ is estimated based on the effective specific gravity of the aggregate mixtures. The effective specific gravity of aggregate mixture is assumed to be equal to the saturated surface dry specific gravity or to the average value of bulk and to the apparent specific gravity of aggregate mixture.

Both of the air voids percent and optimum asphalt content of a pavement mixture are affected by the determination method of $G_{\mathrm{mm}}$, specially calculation of $\mathrm{G}_{\mathrm{mm}}$ by Rice test and the estimation equation. 


\subsection{Study Objective}

The main objective of this paper is to discuss the impact of $\mathrm{G}_{\mathrm{mm}}$ Calculation method on the percent of air voids in pavement mixture and on the optimum asphalt content of a pavement mixture.
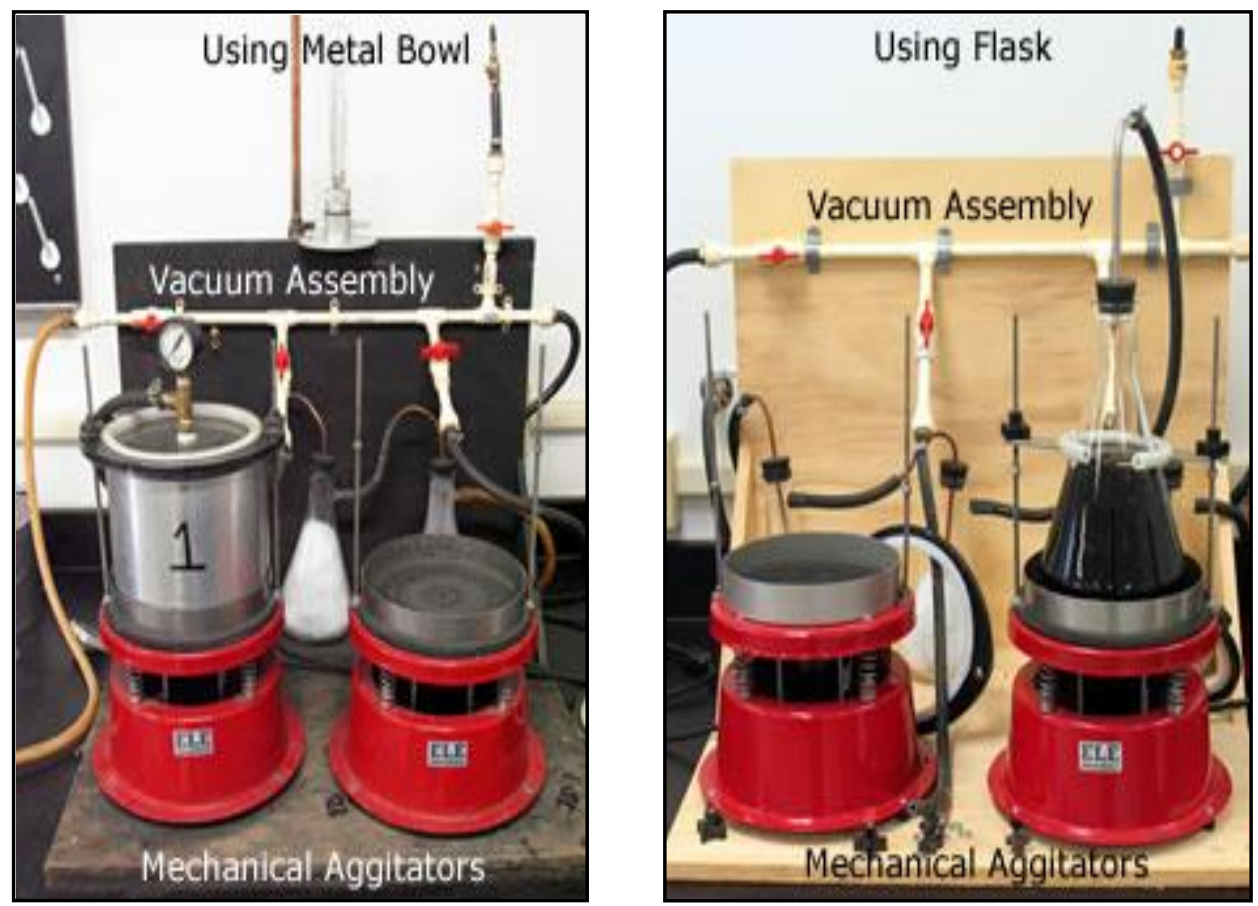

Fig. 1. Theoretical maximum specific gravity of a bituminous paving mixture $\left(\mathrm{G}_{\mathrm{mm}}\right)$ test apparatus, rice test apparatus [9].

\section{Experimental Program}

Four aggregates mixtures design specifications and two types of aggregates were used to perform eight HMA designs. The design mix specifications include the following:

1) Class A aggregate gradation, Riyadh Municipality

2) Class 1 aggregate gradation, Ministry of Transportation, Saudi Arabia.

3) Class $3 \mathrm{~B}$ course graded aggregate gradation, Egyptian code for urban and rural works.

4) Class $2 \mathrm{C}$ open graded aggregate gradation specifications, Egyptian code for urban and rural works.

Table 1 shows the aggregate gradation for the four aggregate mixtures which mentioned above. The previous four aggregate mixtures were produced with two types of aggregates as follows:

1) Limestone aggregate.

2) Basalt aggregates.

Eight MARSHALL mix design were performed using the four aggregate gradations specifications, which mentioned in Table 1, and two types of aggregate (limestone, basalt). $\mathrm{G}_{\mathrm{mm}}$ was determined for all mixes as following:

1) Measured: By measuring $G_{m m}$ using the Rice test. It will be referred to, as $G_{m m}-m[8,9]$.

2) Estimated: By estimating $G_{\mathrm{mm}}$ using the effective specific gravity of aggregate mixtures which assumed to be equal to the following [6, 7]:

a) Saturated surface dry specific gravity. It will be referred to, as $G_{m m}-e_{1}[7]$.

b) Average value of bulk and apparent specific gravity. It will be referred to, as $G_{m m}-e_{2}[7]$.

Also, the percent of air voids at each design asphalt content level and optimum asphalt content were calculated three times. The first, by using $G_{m m}-m$, the second by using $G_{m m}-e_{1}$, and the third by using $G_{m m}-$ $\mathrm{e}_{2}$. 
Table 1. Aggregate gradation for aggregate mixtures.

\begin{tabular}{|c|c|c|c|c|c|c|c|c|c|}
\hline \multicolumn{8}{|c|}{ Aggregate Gradation Specification/Code } & \multirow{3}{*}{\multicolumn{2}{|c|}{ SIEVE SIZE }} \\
\hline \multicolumn{2}{|c|}{ RG_Open_2C } & \multicolumn{2}{|c|}{ EG_Course_3B } & \multicolumn{2}{|c|}{ SA_MOT_1 } & \multicolumn{2}{|c|}{ SA_RM_A } & & \\
\hline U.L & L.L & U.L & L.L & U.L & L.L & U.L & L.L & & \\
\hline \multicolumn{2}{|c|}{100} & \multicolumn{2}{|c|}{100} & \multicolumn{2}{|c|}{100} & \multicolumn{2}{|c|}{100} & 19 & $3 / 4 "$ \\
\hline 100 & 70 & 100 & 75 & 90 & 75 & 95 & 80 & 12.5 & $1 / 2^{\prime \prime}$ \\
\hline 75 & 45 & 85 & 60 & 79 & 64 & & & 9.5 & $3 / 8^{\prime \prime}$ \\
\hline 40 & 20 & 55 & 35 & 56 & 41 & 62 & 48 & 4.75 & $\# 4$ \\
\hline 20 & 5 & 35 & 20 & & & & & 2.36 & $\# 8$ \\
\hline- & - & - & - & 37 & 23 & 45 & 32 & 2 & $\# 10$ \\
\hline- & - & - & - & - & - & - & - & 1.18 & $\# 16$ \\
\hline- & - & 22 & 10 & - & - & - & - & 0.6 & $\# 30$ \\
\hline- & - & - & - & 20 & 7 & 26 & 16 & 0.425 & $\# 40$ \\
\hline- & - & 16 & 6 & - & - & - & - & 0.3 & $\# 50$ \\
\hline- & - & - & - & 13 & 5 & 18 & 8 & 0.18 & $\# 80$ \\
\hline- & - & 12 & 4 & - & - & - & - & 0.15 & $\# 100$ \\
\hline 4 & 0 & 8 & 2 & 8 & 3 & 8 & 4 & 0.075 & $\# 200$ \\
\hline \multicolumn{2}{|c|}{$S A_{-} M O T_{-} A:$} & \multicolumn{8}{|c|}{ Class $\boldsymbol{A}$ aggregate gradation specifications, Riyadh Municipality. } \\
\hline \multirow{2}{*}{\multicolumn{2}{|c|}{ SA_MOT_1: }} & \multicolumn{8}{|c|}{ Class 1 aggregate gradation specifications, Ministry of Transportation, Saudi Arabia. } \\
\hline & EG_Course $3 B$ : & \multicolumn{8}{|c|}{ Class $3 \boldsymbol{B}$ Course graded aggregate gradation specifications, Egyptian code for urban and rural works. } \\
\hline \multirow{2}{*}{\multicolumn{2}{|c|}{ RG_Open_2C: }} & \multirow{2}{*}{\multicolumn{8}{|c|}{ Class $2 C$ Open graded aggregate gradation specifications, Egyptian code for urban and rural works. }} \\
\hline & & \multicolumn{7}{|c|}{ 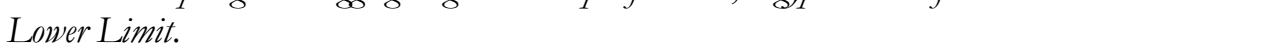 } & \\
\hline LL: & & \multicolumn{8}{|c|}{ Upper Limit. } \\
\hline
\end{tabular}

\section{Data Analysis}

\subsection{Percent of Air Voids}

The Percent of air voids at each design asphalt content level during MARSHALL mix design for the eight designs were calculated by using $G_{m m}-m, G_{m m}-e_{1}$, and $G_{m m}-e_{2}$. Figure 2 shows the relation between the percent of air voids, which calculated using $G_{m m}-m\left(A V_{m}\right)$, and the percent of air voids, which calculated by using $G_{m m}-e_{1}\left(A V_{e 1}\right)$, for limestone and basalt asphalt mixes. It seems from the figure that $A V_{m}$ is lower than $\mathrm{AV}_{\mathrm{e} 1}$ for limestone asphalt mixes, and it is higher than $\mathrm{AV}_{\mathrm{e} 1}$ for basalt asphalt mixes.

Figure 3 shows the relation between $A V_{m}$ and percent of air voids, which calculated using $G_{m m}-e_{2}$ $\left(A V_{e 2}\right)$, for limestone and basalt asphalt mixes. It seems from the figures that $A V_{m}$ is lower than $A V_{e 2}$ for limestone and basalt asphalt mixes.

Regression analysis of the data presented in Figs. 2 and 3 was figured out using the regression analysis technique through the MINITAB statistical software version 13.2. The regression process was performed to get a group of models that relate $A V_{m}$ and both of $A V_{e 1}, A V_{e 2}$ for limestone and basalt aggregate study samples. The models is used to get the effect of changing $\mathrm{G}_{\mathrm{mm}}$ on the values of air voids and asphalt content of asphalt mixture. The dependent variable was $A V_{m}$ and the independent variable was $A V_{e}$. The selected models were linear. Figure 4 shows $A V_{m}$ versus $A V_{\mathrm{e} 1}$ for both limestone and basalt asphalt mixes. Eq. (4) presents the limestone model, while Eq. (5) presents basalt model.

For limestone aggregate: $\quad \mathrm{AV}_{\mathrm{m}}=0.9894\left(\mathrm{AV}_{\mathrm{e} 1}\right)-0.3611$

For basalt aggregate: $\quad \mathrm{AV}_{\mathrm{m}}=0.9967\left(\mathrm{AV}_{\mathrm{e} 1}\right)+0.2508$

where $A V_{m}$ : percent of air voids calculated using $G_{m m}-m$;

$A V_{\mathrm{e} 1}$ : percent of air voids calculated using $\mathrm{G}_{\mathrm{mm}}-\mathrm{e}_{1}$.

Figure 4 shows that as $A V_{m}$ increases, $A V_{e}$ increases. Moreover, $A V_{m}$ is lower than $A V_{e 1}$ for limestone mixes; however, $A V_{m}$ is higher than $A V_{\mathrm{e} 1}$ for basalt mixes.

The square root coefficients of determination $\left(\mathrm{R}^{2}\right)$ are 0.969 and 0.998 for limestone and basalt asphalt mixes, respectively. In addition, the values for standard error of estimate (S) for limestone and basalt are 0.4142 and 0.1124 . 


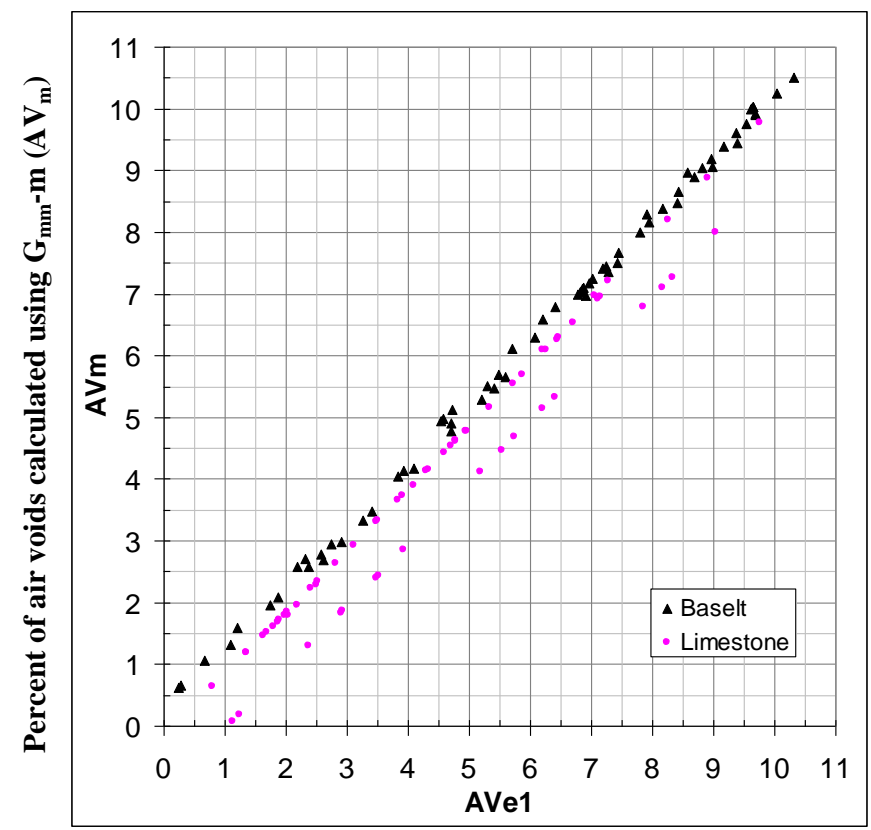

Percent of air voids calculated using $G_{m m}-e_{1}\left(A V_{e 1}\right)$

Fig. 2. $A V_{\mathrm{m}}$ versus $A V_{\mathrm{e} 1}$ for limestone and basalt test sample.

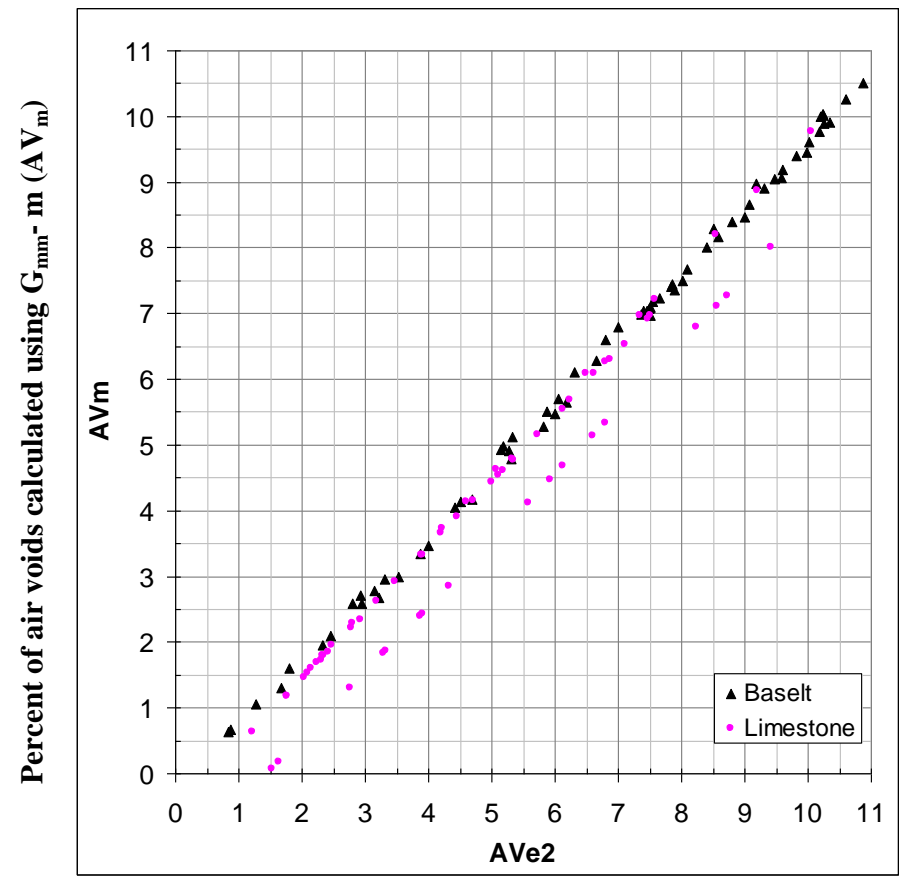

Percent of air voids calculated using $G_{m m}-e_{2}\left(A V_{e 2}\right)$

Fig. 3. $\mathrm{AV}_{\mathrm{m}}$ versus $\mathrm{AV}_{\mathrm{e} 2}$ for limestone and basalt test sample.

The comparison of the value of $\mathrm{AV}_{\mathrm{m}}$ with the value of $\mathrm{AV}_{\mathrm{e} 1}$ at a range between 3 to $5 \%$, which was estimated the percent of air voids using Eq. (4) and (5), reveals that for limestone $A V_{m}$ is lower than $A V_{\mathrm{e} 1}$ by $10 \%$, and for basalt $A V_{m}$ is greater than $A V_{\mathrm{e} 1}$ by $6 \%$. Figure 5 shows $A V_{m}$ versus $A V_{\mathrm{e} 2}$ for both limestone and basalt aggregate study samples. Eq. (6) presents the limestone model, while Eq. (7) presents basalt model.

For limestone aggregate: $\quad \mathrm{AV}_{\mathrm{m}}=0.9928\left(\mathrm{AV}_{\mathrm{e} 2}\right)-0.7431$

For basalt aggregate: $\quad \mathrm{AV}_{\mathrm{m}}=0.9941\left(\mathrm{AV}_{\mathrm{e} 2}\right)-0.334$

where: $A V_{\mathrm{e} 2}$ : percent of air voids calculated using $\mathrm{G}_{\mathrm{mm}}-\mathrm{e}_{2}$. 
The figure shows that as the value of $A V_{m}$ increases, $A V_{e}$ increases and $A V_{m}$ is lower than $A V_{e 2}$ for limestone and basalt mixes.

The square root coefficients of determination $\left(\mathrm{R}^{2}\right)$ are 0.967 and 0.998 for limestone and basalt asphalt mixes, respectively. In addition, the standard error of estimate (S) values for limestone and basalt are 0.4286 and 0.1138 , respectively. The comparison between the value of $\mathrm{AV}_{\mathrm{m}}$ and the value of $\mathrm{AV}_{\mathrm{e} 2}$ at a range between 3 to 5\%, which estimated percent air voids by using Eq. (6), and Eq. (7) shows that $A V_{m}$ values for limestone and basalt asphalt mixes are lower than $\mathrm{AV}_{\mathrm{e} 2}$ by $20 \%$, and by $9 \%$, respectively.

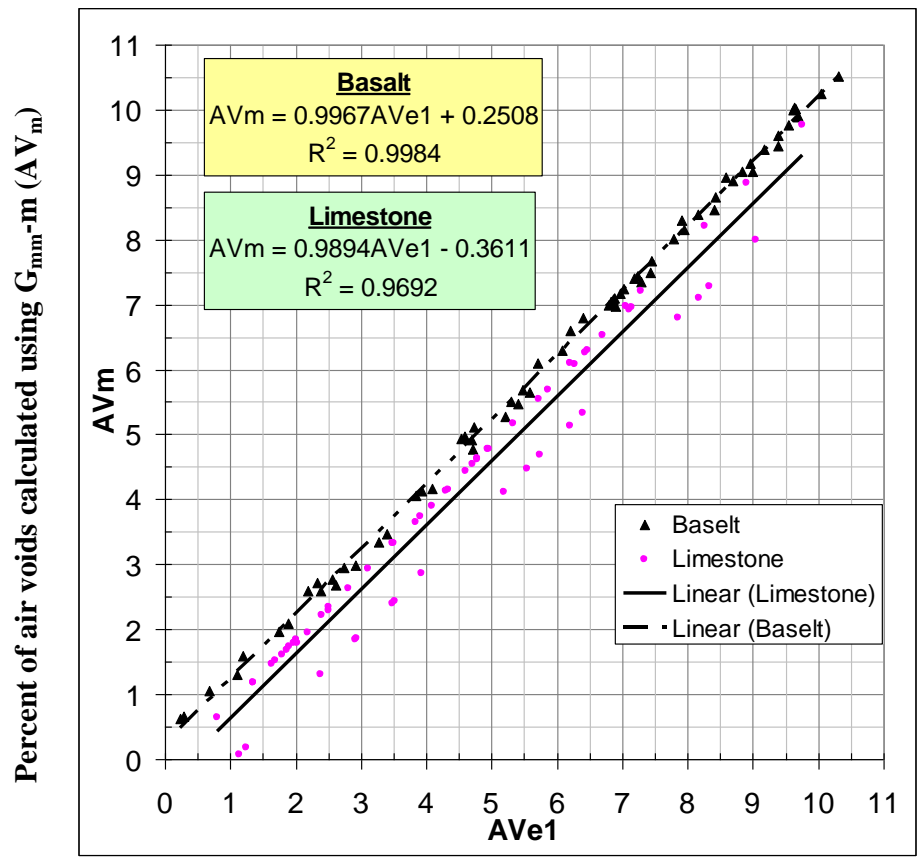

Percent of air voids calculated using $\mathbf{G}_{\mathrm{mm}^{-}} \mathrm{e}_{\mathbf{1}}$ (AVe1)

Fig. 4. Relationship between $A V_{m}$ and $A V_{e 1}$ for test samples.

\subsection{Optimum Asphalt Content of Pavement Mixture}

The optimum asphalt content of pavement mixture for the design mixes was calculated 3 times using MARSHALL method. The first one was calculated using $G_{m m}-m$ and called $\left(A_{m}\right)$; the second one was calculated using $G_{m m}-e_{1}$ and called $\left(A C_{e 1}\right)$; finally, the last one was calculated using $G_{m m}-e_{2}$ and called $\left(A C_{e 2}\right)$. Figure 6 shows the data of $\mathrm{AC}_{\mathrm{m}}$ versus the data of $\mathrm{AC}_{\mathrm{e} 1}$. According to the figure, the value of $\mathrm{AC}_{\mathrm{m}}$ increases, the value of $\mathrm{AC}_{\mathrm{e}}$ increases; however, $\mathrm{AC}_{\mathrm{m}}$ value is lower than $\mathrm{AC}_{\mathrm{e} 1}$ for limestone, while $\mathrm{AC}_{\mathrm{m}}$ value is higher than $\mathrm{AC}_{\mathrm{e} 1}$ for basalt.

The regression analysis indicated that the selected models were linear as presented in Fig. 6 as follows:

For limestone aggregate: $\quad \mathrm{AC}_{\mathrm{m}}=0.8333\left(\mathrm{AC}_{\mathrm{e} 1}\right)+0.54117$

For basalt aggregate: $\quad \mathrm{AC}_{\mathrm{m}}=1.0403\left(\mathrm{AC}_{\mathrm{e} 1}\right)-0.0963$

where:

$A C_{m}$ : optimum asphalt content of pavement mixture using $G_{m m}-m$,

$A_{\mathrm{e} 1}$ : optimum asphalt content of pavement mixture using $\mathrm{G}_{\mathrm{mm}}-\mathrm{e}_{1}$,

The square root coefficients of determination $\left(\mathrm{R}^{2}\right)$ for limestone and basalt asphalt mixes are 0.387 and 0.989 , respectively. The comparison of the value of $\mathrm{AC}_{\mathrm{m}}$ with the value of $\mathrm{AC}_{\mathrm{e} 1}$, which computed using $\mathrm{Eq}$. (8) and (9), reveals that $\mathrm{AC}_{\mathrm{m}}$ is lower than $\mathrm{AC}_{\mathrm{e} 1}$ by $5 \%$ for limestone, and $\mathrm{AC}_{\mathrm{m}}$ is higher than $\mathrm{AC}_{\mathrm{e} 1}$ by $2 \%$ for basalt asphalt mixes.

Figure 7 shows the data of $\mathrm{AC}_{\mathrm{m}}$ versus the data of $\mathrm{AC}_{\mathrm{e} 2}$. It shows that when the value of $\mathrm{AC}_{\mathrm{m}}$ increases, the value of $\mathrm{AC}_{\mathrm{e}}$ increases; however, $\mathrm{AC}_{\mathrm{m}}$ value is lower than $\mathrm{AC}_{\mathrm{e} 2}$ for limestone and basalt aggregate. The regression analysis indicated that the selected models were linear as presented in Fig. 7 as follows:

For limestone aggregate: $\quad \mathrm{AC}_{\mathrm{m}}=1.0534\left(\mathrm{AC}_{\mathrm{e} 2}\right)-0.5893$

For basalt aggregate: $\quad \mathrm{AC}_{\mathrm{m}}=0.8519\left(\mathrm{AC}_{\mathrm{e} 2}\right)+0.6306$ 
where $A_{\mathrm{e} 2}$ : optimum asphalt content of pavement mixture using $\mathrm{G}_{\mathrm{mm}}-\mathrm{e}_{2}$.

The square root coefficients of determination $\left(\mathrm{R}^{2}\right)$ for limestone and basalt asphalt mixes are 0.845 and 0.961 , respectively. The comparison of the value of $\mathrm{AC}_{\mathrm{m}}$ with the value of $\mathrm{AC}_{\mathrm{e} 2}$, which computed using Eq. (10) and (11), reveals that $\mathrm{AC}_{\mathrm{m}}$ values for limestone and basalt asphalt mixes are lower than $\mathrm{AC}_{\mathrm{e} 2}$ ones by $7 \%$ and $2 \%$, respectively.

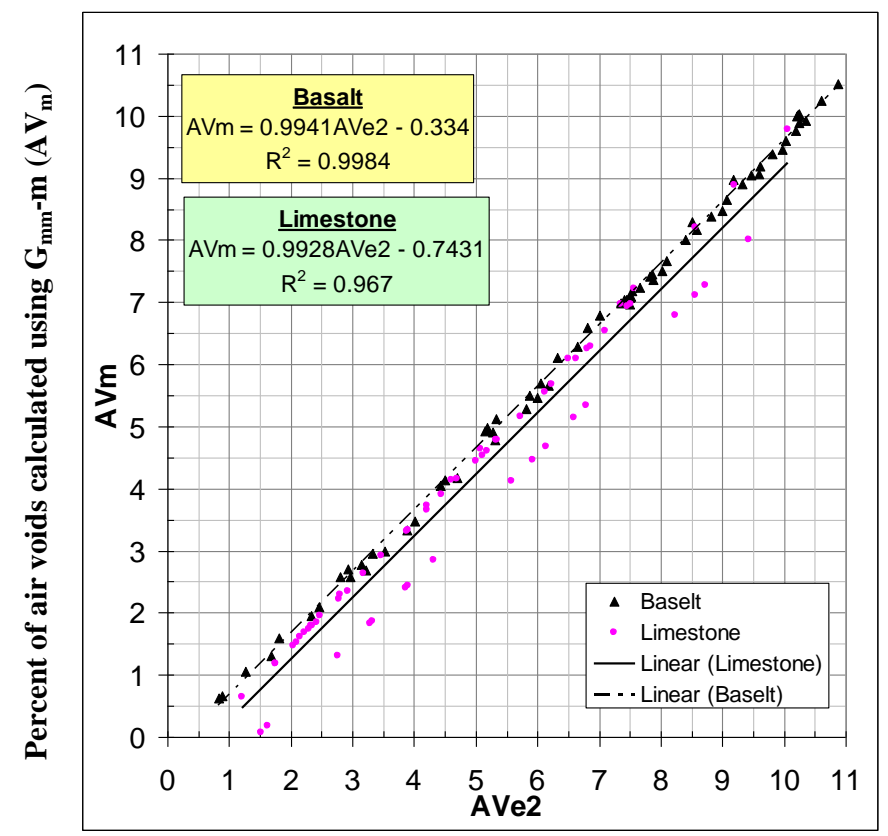

Percent of air voids calculated using $\mathbf{G}_{\mathrm{mm}^{-}} \mathrm{e}_{2}(\mathrm{AVe} 2)$

Fig. 5. Relationship between $A V_{m}$ and $A V_{e 2}$ for test samples.

\subsection{Effects on Percent of Air Voids at Optimum Asphalt Content of Pavement Mixture}

The percent of air voids at optimum asphalt content of pavement mixture is impacted by the $G_{\mathrm{mm}}$ calculation method. In case of performing mix design procedures with $G_{m m}$, which estimated by the equation, the true percent of air voids in the designed mix will be $A V_{m}$; however, the design sheet will include $A V_{e}$. The $A V_{m}$ value usually differs than $A V_{e}$. This means that at selected estimated optimum asphalt content $\left(A C_{e}\right)$, the true percent of air voids $\left(A V_{m}\right)$ may be near to the upper or lower limits of the specification ranges.

Figure 8 shows $A V_{m}$ and $A V_{\mathrm{e} 1}$ at the optimum asphalt content $\left(A C_{\mathrm{e} 1}\right)$ for the first three pavement mixtures was presented in Table 1 for the two aggregate types. It can be noticed that the true percent of air voids $\left(A V_{m}\right)$ for the limestone mixes are less than the estimated $A V_{e 1}$, and reaches the lower specification limit for mix number (2).

Figure 9 shows $\mathrm{AV}_{\mathrm{m}}$ and $\mathrm{AV}_{\mathrm{e} 2}$ at optimum asphalt content $\left(\mathrm{AC}_{\mathrm{e} 2}\right)$ for the first three pavement mixtures was presented in Table 1 for the two aggregate types. It is obvious that the true percent of air voids $\left(A V_{m}\right)$ for the limestone and basalt mixes are less than the estimated $A V_{\text {e2. }}$ Moreover, they reach the lower specification limit for one of the mixes.

On the other hand, the analysis for optimum asphalt content indicated that $\mathrm{AC}_{\mathrm{m}}$ for limestone is lower than $\mathrm{AC}_{\mathrm{e} 1}$ by $5 \%$ and $\mathrm{AC}_{\mathrm{m}}$ is lower than $\mathrm{AC}_{\mathrm{e} 2}$ by $7 \%$. This means that the designed mixes which made by limestone have exactly lower air voids value and higher asphalt content. This may be one of the reasons of appearing bleeding asphalt distresses. Thus, it is very important to apply measuring $G_{\mathrm{mm}}$ by Rice test in asphalt mix design. 




Asphalt content for mixes designed by using $\mathbf{G}_{\mathbf{m m}}-\mathbf{e}_{\mathbf{1}}$ (AC_e1)

Fig. 6. Relationship between $\mathrm{AC}_{\mathrm{m}}$ and $\mathrm{AC}_{\mathrm{e} 1}$ for test samples.

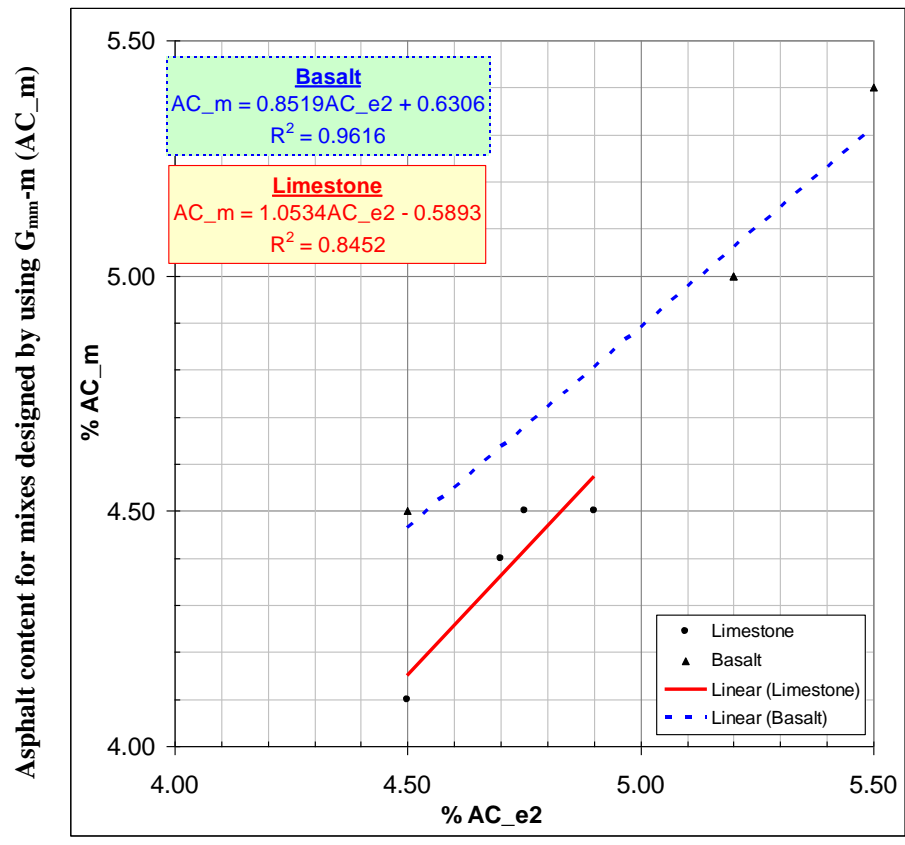

Asphalt content for mixes designed by using $\mathbf{G}_{\mathrm{mm}}-\mathbf{e}_{\mathbf{2}}\left(\mathrm{AC} \_\mathrm{e} 2\right)$

Fig. 7. Relationship between $\mathrm{AC}_{\mathrm{m}}$ and $\mathrm{AC}_{\mathrm{e} 2}$ for test samples.

\subsection{Relationship Between Measured and Estimated Theoretical Maximum Specific Gravity}

Figure 10 shows the measured $G_{m m}$ using the Rice test $\left(G_{m m}-m\right)$ versus both of estimated $G_{m m}$ using saturated surface dry specific gravity $\left(G_{m m}-e_{1}\right)$ and estimated $G_{m m}$ using average value of bulk and apparent specific gravity $\left(\mathrm{G}_{\mathrm{mm}}-\mathrm{e}_{2}\right)$ for limestone and basalt.

It seems from the figures that the measured $G_{\mathrm{mm}}$ is usually lower than the estimated one for limestone while the measured $G_{m m}$ is higher than the $G_{m m}-e_{1}$ and lower than $G_{m m}-e_{2}$ for basalt. 


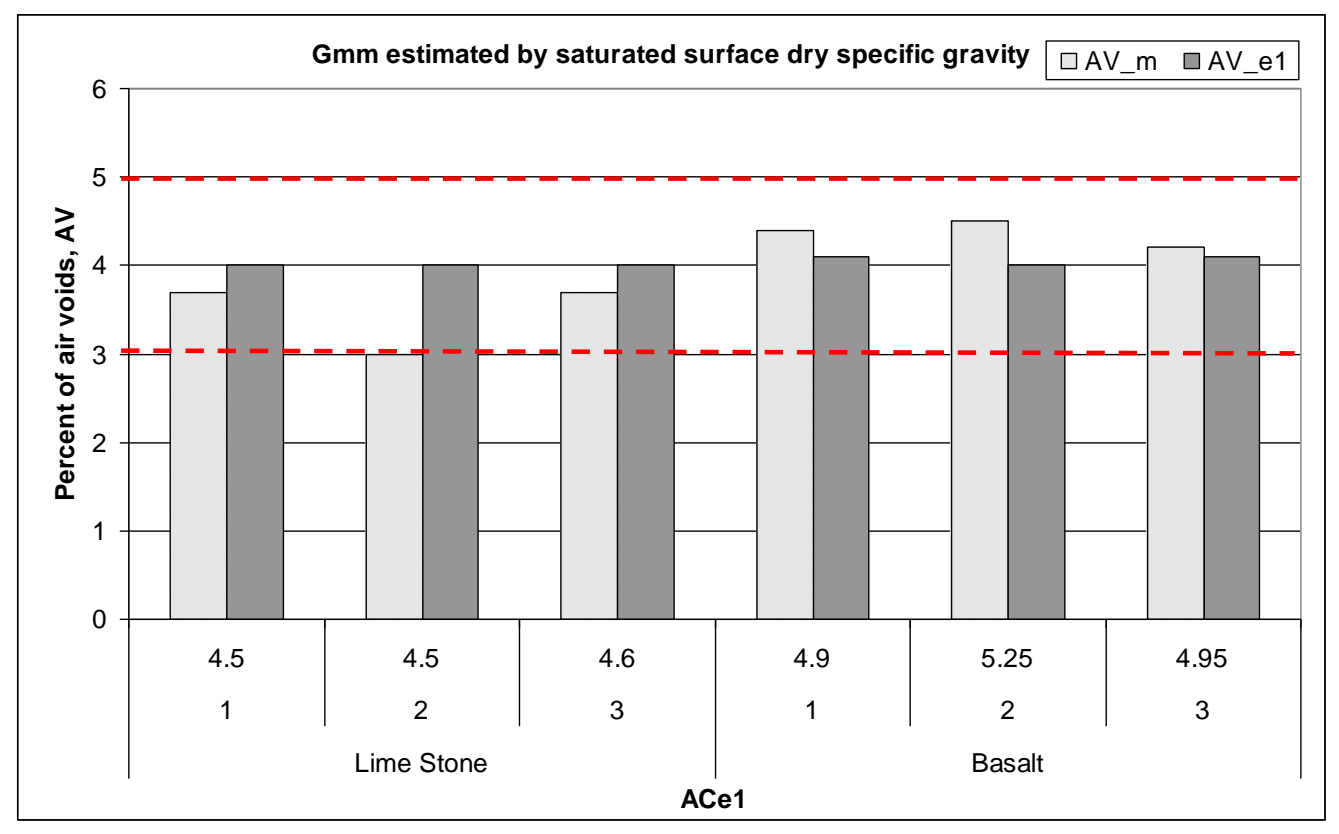

Asphalt content for mixes designed by using $G_{m m}-e_{1}\left(A C \_e 1\right)$

Fig. 8. Effects on percent of air voids at optimum asphalt content $\mathrm{AC}_{\mathrm{e} 1}$.

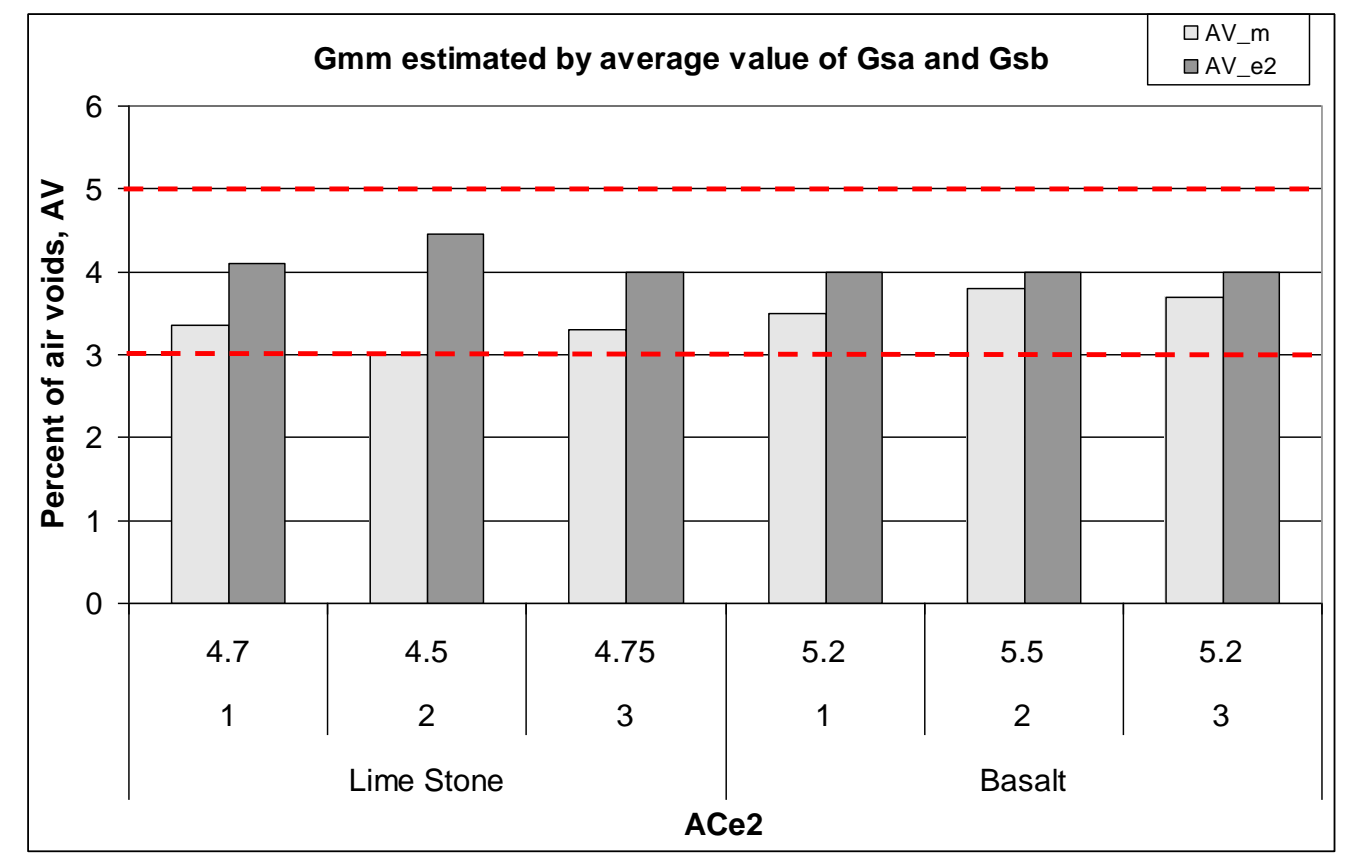

Asphalt content for mixes designed by using $\mathbf{G}_{\mathbf{m m}^{-}} \mathbf{e}_{\mathbf{2}}$ (AC_e2)

Fig. 9. Effects on percent of air voids at optimum asphalt content $\mathrm{AC}_{\mathrm{e} 2}$. 


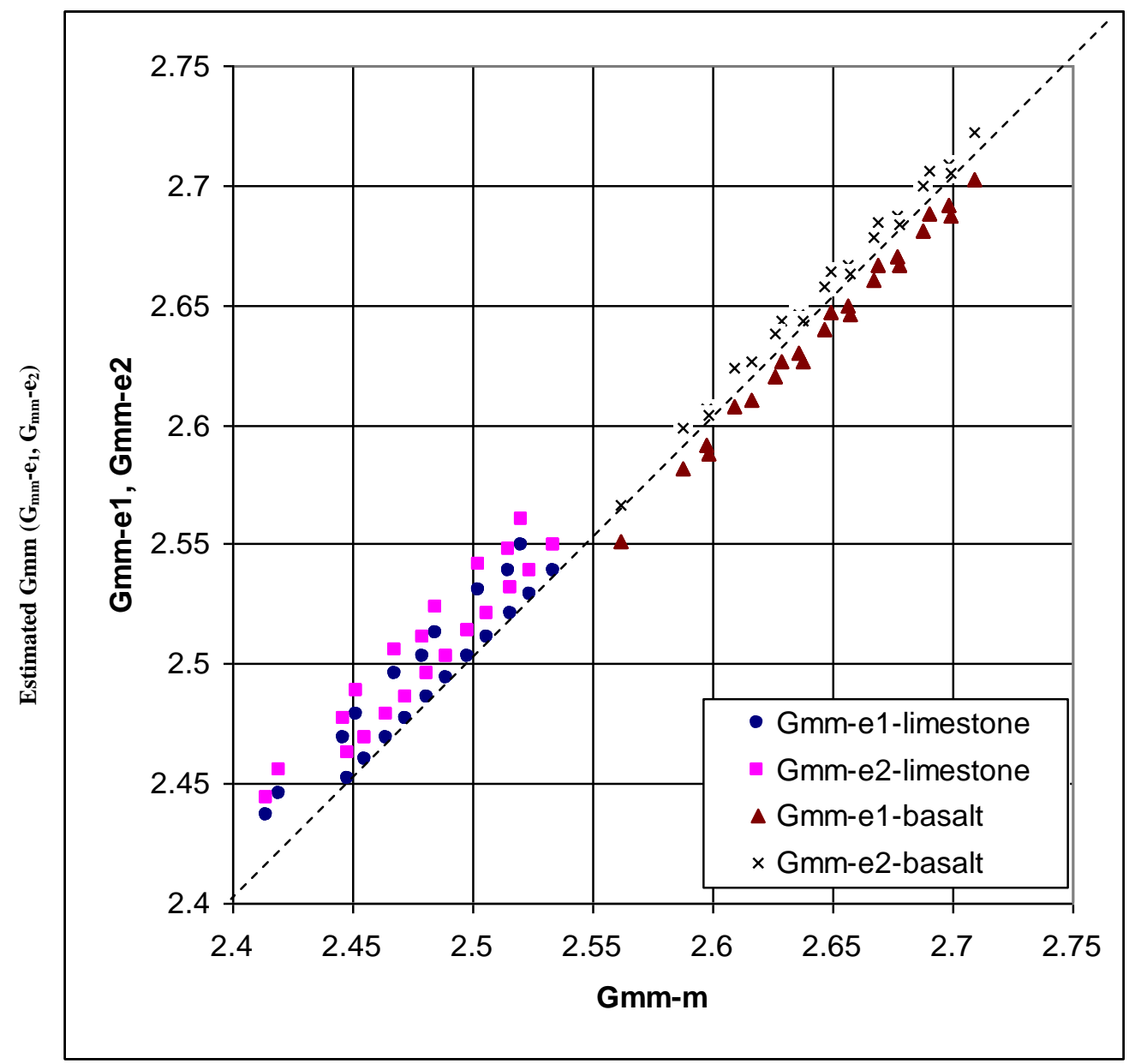

Measured $\mathbf{G}_{\mathrm{mm}}\left(\mathbf{G}_{\mathrm{mm}}-\mathbf{m}\right)$

Fig. 10. $G_{m m}-m$ vs. $G_{m m}-e_{1}$ and $G_{m m}-e_{2}$ for limestone and basalt test.

\section{Conclusions And Recommendations}

In this study, the impact of changing theoretical maximum specific gravity of asphalt mixture on the properties of asphalt mixes has been investigated thorough an extensive experimental program. The following conclusions and recommendations can be classified as follows and may be applied for Egypt and similar countries which not apply rice test for MARSHALL design procedures:

1) The percent of air voids using $G_{m m}-m\left(A V_{m}\right)$, could be predicted from the independent variables percent of air voids calculated by $\mathrm{G}_{\mathrm{mm}}-\mathrm{e}_{1}$ using Eq. (4) for limestone aggregate and Eq. (5) for basalt aggregate. From these equations, it could obtain more than 96 percent information about $A V_{m}$ from $A V e$ within the studied data range, and may be used to get $A V_{m}$ in case of non availability of Rice test.

2) The percent of air voids using $G_{m m}-m\left(A V_{m}\right)$ can predicted from the independent variables percent of air voids which calculated by $\mathrm{G}_{\mathrm{mm}} \mathrm{e}_{2}$ using Eq. (7) for limestone aggregate and Eq. (8) for basalt aggregate. From these equations, it could obtain more than 96 percent information about $A V_{m}$ from $A V_{e}$ within the studied data range, and may be used to get $A V_{m}$ in case of non availability of Rice test.

3) The comparison of the value of $\mathrm{AV}_{\mathrm{m}}$ with the value of $\mathrm{AV}_{\mathrm{e} 1}$ at a range between $3 \%$ to $5 \%$ estimated percent air voids reveals that for limestone $A V_{m}$ is lower than $A V_{e 1}$ by $10 \%$, and $A V_{m}$ is greater than $A V_{\mathrm{e} 1}$ by $6 \%$ for basalt.

4) The comparison of the value of $\mathrm{AV}_{\mathrm{m}}$ with the value of $\mathrm{AV}_{\mathrm{e} 2}$ at a range between $3 \%$ to $5 \%$ estimated percent air voids reveals that $\mathrm{AV}_{\mathrm{m}}$ values for limestone and basalt asphalt mixes are lower than $\mathrm{AV}_{\mathrm{e} 2}$ by $20 \%$ and $9 \%$, respectively.

5) The optimum asphalt content using $G_{m m}-m\left(A C_{m}\right)$, can predicted from the independent variables optimum asphalt content which calculated by $\mathrm{G}_{\mathrm{mm}}-\mathrm{e}_{1}\left(\mathrm{AC}_{\mathrm{el}}\right)$ using Eq. (8) for limestone aggregate 
and Eq. (9) for basalt aggregate. From these equations, it could obtain 81 percent information about $\mathrm{AC}_{\mathrm{m}}$ from $\mathrm{ACe} 1$ within the studied data range.

6) The optimum asphalt content using $G_{m m}-m\left(A C_{m}\right)$, can predicted from the independent variables optimum asphalt content calculated by $\mathrm{G}_{\mathrm{mm}}-\mathrm{e}_{2}\left(\mathrm{AC}_{\mathrm{e} 2}\right)$ using Eq. (10) for limestone aggregate and Eq. (11) for basalt aggregate. From these equations, it could obtain 38, 98 percent information about $\mathrm{AC}_{\mathrm{m}}$ from $\mathrm{AC}_{\mathrm{e} 2}$ for limestone and basalt aggregates, respectively, within the studied data range.

7) The comparison of the value of $\mathrm{AC}_{\mathrm{m}}$ with the value of $\mathrm{AC}_{\mathrm{e} 1}$ using the previous equations shows that $\mathrm{AC}_{\mathrm{m}}$ is lower than $\mathrm{AC}_{\mathrm{e} 1}$ by $5 \%$ for limestone; however, $\mathrm{AC}_{\mathrm{m}}$ is higher than $\mathrm{AC}_{\mathrm{e} 1}$ by $2 \%$ for basalt.

8) The comparison of the value of $\mathrm{AC}_{\mathrm{m}}$ with the value of $\mathrm{AC}_{\mathrm{e} 2}$ using the previous equations reveals that $\mathrm{AC}_{\mathrm{m}}$ values for limestone and basalt asphalt mixes are lower than $\mathrm{AC}_{\mathrm{e} 2}$ by $7 \%$ and $2 \%$, respectively.

9) Rice test should be applied for MARSHALL design procedures mentioned in Egyptian code for urban and rural works, and in all pavement mix designs performed for Egyptian roads.

\section{Acknowledgments}

The author wishes to thank the engineering staff of KATTAN Consultant Office for greet help and facilitation during the laboratory tests, specially Eng. M. R. F. Kattan, Eng. M. Bayyoumi, and Eng. Abdullah Ibrahim.

\section{References}

[1] (May 2009) Flexible Pavement Construction [Online]. http://training.ce.washington.edu/WSDOT/ Modules/07_construction/07-6_body.htm

[2] R. N. Linden, J. P. Mahoney, and N. C. Jackson, "The effect of compaction on asphalt concrete performance," presented at the 1989 Annual Meeting of the Transportation Research Board, Washington, DC, 1989.

[3] F. L. Roberts, P. S. Kandhal, E. R. Brown, D. Y. Lee, and T. W. Kennedy, "Hot mix asphalt materials, mixture design, and construction," National Asphalt Paving Association Education Foundation, Lanham, MD, 1996.

[4] J. A. Scherocman, "Guidelines for compacting asphalt concrete pavement," Better Roads, vol. 54, no. 3, pp. 12-17, Mar. 1984.

[5] T. R. Murphy and R. A. Bentsen, MARSHALL MIX DESIGN: Getting the most out of your MARSHALL MIXES. Norridge, IL: Humboldt Mfg. Co., 2001.

[6] Standard Test Method for Theoretical Maximum Specific Gravity and Density of Bituminous Paving Mixtures, American Society for Testing and Materials ASTM International Designation: D 2041 - 03a, 2005.

[7] Egyptian Code for Urban and Rural Roads Works, Part Four: Roads Materials and their Testing, 1st ed., 1998.

[8] Mix Design Methods for Asphalt Concrete and Other Hot-Mix Types. The Asphalt Institute Manual Series No. 2 (MS-2), Mar. 1979.

[9] Standard Specifications for Transportation Materials and Methods of Sampling and Testing, 17th ed., Maximum Specific Gravity of Bituminous Paving Mixtures, AASHTO Designation: T209-94, 1995.

[10] Preparation and Construction of the Road Projects Handbook, Ministry of Transport, General Authority of Roads and Bridges and Land Transport (GARLT), Egypt, Cairo, 1989. 